\title{
Effect of immunization of hamsters against recombinant P26h on fertility rates
}

\author{
C. Gaudreault ${ }^{1}$, L. Montfort ${ }^{1}$ and R. Sullivan ${ }^{2 *}$ \\ ${ }^{1}$ Centre de Recherche en Biologie de la Reproduction and Département d'Obstétrique- \\ Gynécologie, Faculté de Médecine, Université Laval, 2705 Blvd. Laurier, Ste-Foy, \\ QC GIV 4G2, Canada; and 'Unité d'Ontogénie-Reproduction, Centre de Recherche, \\ Centre Hospitalier de I'Université Laval, 2705 Blvd Laurier, Ste-Foy, QC GIV 4G2, Canada
}

Despite the various contraceptive methods available, an effective and inexpensive method remains to be established. Immunocontraception may help to achieve this goal. P26h has been proposed as a candidate for the development of a male contraceptive vaccine. P26h, a hamster sperm protein, interacts with the zona pellucida. Furthermore, in vivo fertilization can be blocked completely by active immunization of male hamsters against P26h. Maltose binding protein (MBP)-P26 shares antigenic determinants with the native $\mathrm{P26h}$ present on cauda epididymal spermatozoa. The aim of the present study was to reproduce the immunocontraceptive properties of native P26h by immunizing male hamsters against a recombinant $\mathbf{P 2 6}$ h fused with a maltose binding

\section{Introduction}

The development of a contraceptive vaccine has been of interest for more than two decades. This approach represents a promising method of population control (Naz, 1999) and indeed, in countries with high birth rates and where no birth control is available, contraceptive vaccines could provide an inexpensive method of family planning (Naz, 1996). Alternatively, contraceptive vaccinations have also been proposed for controlling populations of pest species, where traditional methods of increasing mortality are ineffective on a long-term basis (Tyndale-Biscoe, 1994).

The concept of immunocontraception is based on the contention that immunization against molecules involved exclusively in reproductive processes will result in the production of circulating antibodies neutralizing the function of these molecules, thus interfering with successful fertilization (Mandelbaum et al., 1987; Chang et al., 1993; Talwar, 1999). This concept is supported by results from vasectomized and infertile men as well as from studies on animals. Indeed, infertility may be associated with antisperm antibodies (ASA) in infertile and vasectomized men (Liskin et al., 1983; Bronson et al., 1984). Moreover,

*Correspondence

Email: robert.sullivan@crchul.ulaval.ca protein (MBP). Active immunization of male hamsters with the MBP-P26h showed that specific anti-P26h circulating IgGs could be generated. Mating of immunized male hamsters with superovulated females resulted in a significant decrease, $20-25 \%$, in the fertilization rate. This result is in agreement with results from in vitro sperm-zona pellucida binding assays. Indeed, the antirecombinant P26h IgGs showed lower inhibitory properties when compared with anti-native P26h IgG. Despite the high anti-P26h IgG titres generated in hamsters, histological studies showed that active immunization has no pathological sequelae to the reproductive tissues. The potential of $\mathrm{P} 26 \mathrm{~h}$ as a candidate for a contraceptive vaccine is discussed. immunization of animals against gamete antigens results in a decrease in fertility (Goldberg, 1986; Bérubé and Sullivan, 1994; Naz and Zhu, 1998).

Effective and safe contraceptive vaccines should block the reproductive process without causing secondary effects. Thus, the target antigen should be specific and restricted to fertilization. Until now, many potential candidates have been proposed for immunocontraception; these include hormones controlling reproductive functions as well as gamete-specific antigens. Indeed, animal vaccination against either the LH-releasing hormone (LHRH), FSH or hCG (Moudgal and Suresh, 1995; Talwar et al., 1985, 1994) showed antifertility effects. Several gamete antigens have also been proposed as candidates for immunocontraception. In females, the zona pellucida proteins, especially ZP3 (Florman and Wassarman, 1985), have been studied extensively. In males, several sperm antigens with potential immunocontraceptive properties have been described and many of these are still being investigated. Among these candidates, lactate dehydrogenase (LDH)-C4 (Goldberg, 1986), PH-20 (Primakoff et al., 1988), sperm protein (SP)-10 (Herr et al., 1990), fertilization antigen (FA)-1 and FA-2 (Naz et al., 1993), cleavage signal (CS)-1 (Naz, 1992), NZ-1 (Naz and Zhu, 1997), NZ-2 (Zhu and Naz, 1998), P34H (Boué et al., 1996) and P26h (Bérubé and Sullivan, 1994) have been studied in detail.

In our laboratory, P26h has been described as a $26 \mathrm{kDa}$ 
hamster sperm protein located on the acrosomal cap. This protein is known to be involved in sperm-zona pellucida interaction as shown by the ability of both anti-P26h IgGs and corresponding Fab fragments to block in vitro spermzona pellucida binding and by its immunocontraceptive properties when used actively to immunize male hamsters (Bérubé and Sullivan, 1994). P26h cDNA was cloned from the testis (Gaudreault et al., 1999), and transcription and translation of P26h in the germ cells have been described by Gaudreault et al. (2001). Recently, the complete P26h cDNA was used to produce a fusion protein with maltose binding protein (MBP) and to raise polyclonal rabbit antisera against the MBP-P26h. A study on cauda epididymal spermatozoa and testicular tissues revealed that these antisera were able to detect P26h on the acrosome of cauda epididymal spermatozoa and a cytoplasmic P26h in late spermatids, showing that MBP-P26h shares antigenic determinants with the native P26h (Gaudreault et al., 2001). The aim of the present study was to determine the effect of the recombinant P26h in active immunization in male hamsters.

\section{Materials and Methods}

\section{Immunization of hamsters}

Sexually mature male golden hamsters (Mesocricetus auratus; Charles River Inc, St-Constant, QC) of proven fertility were immunized with 50, 100 or $150 \mu \mathrm{g}$ MBP-P26h. Two hamsters were immunized for each dose of antigen. The antigen was diluted in $150 \mu$ l D-PBS, pH 7.4 (Gibco $B R L$, Burlington, $\mathrm{ON}$ ), emulsified with an equal volume of complete Freund's adjuvant (Gibco BRL). Booster injections were administered using the same amount of MBP-P26h in $150 \mu \mathrm{l}$ D-PBS emulsified with an equal volume of incomplete Freund's adjuvant (Gibco BRL). All injections were administered i.p. Booster injections were administered each month until high anti-P26h-lgG titres were obtained. Blood was collected by a capillary tube in the orbital sinus in between booster injections and by cardiac puncture at the end of the immunization schedule. Blood samples were maintained at $4^{\circ} \mathrm{C}$ overnight, and serum was recovered by centrifugation at $3000 \mathrm{~g}$ for $15 \mathrm{~min}$ at $4^{\circ} \mathrm{C}$ and frozen at $-80^{\circ} \mathrm{C}$ until used. All animal treatments were performed according to the animal care committee of our institution.

\section{ELISA}

Microtitre plates (VWR, Mont-Royal, QC) were coated with $50 \mu \mathrm{l}$ per well of P26h fused with glutathione Stransferase (GST) $\left(1 \mu \mathrm{ml}^{-1}\right)$ in carbonate-bicarbonate buffer (50 mmol l-1, $\mathrm{pH} 9.6)$ overnight at $4^{\circ} \mathrm{C}$. The plates were washed three times with washing buffer (potassium phosphate $0.01 \mathrm{~mol} \mathrm{I}^{-1}, 0.05 \%(\mathrm{v} / \mathrm{v})$ Tween-20) and blocked further with PBS supplemented with 3\% BSA (ICN, Montréal, QC) for $1 \mathrm{~h}$ at $37^{\circ} \mathrm{C}$. After blocking, the plates were washed three times with washing buffer and $50 \mu \mathrm{l}$ immunized hamster sera at different dilutions in PBS supplemented with 3\% BSA was added to the wells in triplicate. After $1 \mathrm{~h}$ at $37^{\circ} \mathrm{C}$, the plates were washed and treated with peroxidaseconjugated rabbit anti-syrian hamster IgGs (Bio/Can Scientific, Missisauga, ON) diluted 1:10 000 in PBS supplemented with $3 \%$ BSA for $30 \mathrm{~min}$. The plates were then washed and $100 \mu \mathrm{l}$ 2,2'-azino-bis(3-ethylbenzthiazoline-6sulphonic acid; ABTS) solution per well (50 mg ABTS in $100 \mathrm{ml}$ citrate-phosphate buffer $(0.1 \%(\mathrm{w} / \mathrm{v})$ citric acid (ICN), $\left.0.2 \%(\mathrm{w} / \mathrm{v}) \mathrm{Na}_{2} \mathrm{HPO}_{4}(\mathrm{ICN}), \mathrm{pH} 4.6\right)$ was added. Absorbance was measured at $415 \mathrm{~nm}$. ELISA was also performed using sera collected from control hamsters immunized against MBP alone. For this purpose, microtitre plates were coated in the same way using MBP purified protein. Titres were determined by the higher dilution and the presence of hamster IgGs was detected by the peroxidase-conjugated rabbit anti-syrian hamster IgGs (Bio/Can).

\section{Western blot analysis}

Nonidet P-40 (Sigma, Oakville, ON) extracted proteins from cauda epididymal spermatozoa (Sullivan, 1985) were subjected to SDS-PAGE (Laemmli, 1970), and transferred on to a nitrocellulose membrane (Bio-Rad, Hercules, CA; Towbin et al., 1979). Western blots were performed simultaneously in the same SDS-PAGE to avoid any variations between experiments. The different lanes were then cut before they were probed with different antisera. All incubations were performed in parallel. Briefly, the nitrocellulose membranes were blocked with PBS, $\mathrm{pH}$ 7.4, containing $5 \%(\mathrm{w} / \mathrm{v})$ skimmed milk for $1 \mathrm{~h}$ at room temperature. After blocking, the membranes were washed for 10 min with PBS-0.1\% (v/v) Tween-20 (ICN) and incubated with anti-MBP-P26h hamster antisera diluted at $1: 100$ in PBS supplemented with $2.5 \%(\mathrm{v} / \mathrm{v})$ goat serum $(\mathrm{ICN})$. The membranes were washed three times in PBS- $0.1 \%$ Tween-20 for $7 \mathrm{~min}$ and incubated with peroxidase-conjugated anti-syrian hamster IgGs (Bio/Can) diluted at 1:5000 in PBS supplemented with $2.5 \%$ goat serum. Finally, the membranes were visualized using a chemiluminescent substrate of peroxidase according to the supplier's instructions (ECL: Amersham, Life Science, Oakville, ON).

\section{Mating}

Sexually mature female hamsters were injected i.p. with 50 iu equine chorionic gonadotrophin (eCG; Ayerst, Montréal, QC) to induce superovulation. After $72 \mathrm{~h}$, female hamsters were injected with 25 iu hCG (Ayerst) and housed overnight with males of proven fertility. Mating was confirmed by detection of spermatozoa in the vaginal smears. After $36 \mathrm{~h}$, females were killed under an atmosphere of $\mathrm{CO}_{2}$. Oviducts were dissected, and eggs and zygotes were collected by flushing the oviducts with D-PBS. Fertilization was determined by the presence of pronuclei in the cytoplasm of the oocyte. In the present study, each male hamster was mated with three female hamsters. 
Sperm-zona pellucida binding assay

The sperm-zona pellucida binding assay was performed as described by Yanagimachi et al. (1982). Briefly, spermatozoa were collected from cauda epididymides of sexually mature golden hamsters (Mesocricetus auratus) and were capacitated in Tyrode's albumin lactate pyruvate (TALP) medium supplemented with $1.5 \%(\mathrm{w} / \mathrm{v})$ BSA (TALP-1.5\% BSA) at $37^{\circ} \mathrm{C}$ under $5 \% \mathrm{CO}_{2}$ for $3 \mathrm{~h}$. Cumulus-oocyte complexes were collected from 6 -week-old superovulated female hamsters at $18-20 \mathrm{~h}$ after hCG injection, and were then dispersed with hyaluronidase. Oocytes were collected, washed in TALP- $1.5 \%$ BSA and incubated at $37^{\circ} \mathrm{C}$ in $5 \%$ $\mathrm{CO}_{2}$.

IgGs from native P26h and anti-MBP-P26h antiserum were purified using $\mathrm{Hi}_{\mathrm{T}} \mathrm{Trap}^{\mathrm{TM}}$ Protein G Sepharose ${ }^{\mathrm{TM}} \mathrm{HI}$ (Amersham) according to the supplier's protocol. Purified IgGs were further dialysed in $0.5 \%(\mathrm{w} / \mathrm{v})$ ammonium bicarbonate solution and then lyophilized. Finally, the purified IgGs were resuspended in TALP medium supplemented with $1.5 \%(\mathrm{w} / \mathrm{v}) \mathrm{BSA}(\mathrm{ICN})$.

The purified IgGs were added to medium containing oocytes at a final concentration of 0.05 or $0.1 \mu \mathrm{g} \mu \mathrm{l}^{-1}$ for 30 min before the addition of the capacitated spermatozoa suspension $\left(4 \times 10^{5} \mathrm{ml}^{-1}\right)$. Spermatozoa and oocytes were incubated at $37^{\circ} \mathrm{C}$ in $5 \% \mathrm{CO}_{2}$ for 90 min. Eggs were then washed thoroughly by pipetting in TALP medium and observed under phase-contrast microscopy. Results are expressed as the number of spermatozoa bound to the zona pellucida versus the pre-immune $\operatorname{lgG}$ for each treatment.

\section{Histological study}

Histological sections were prepared from tissues collected from immunized hamsters at 2 weeks after the administration of the last injection. Tissues were dissected, fixed by immersion in PBS supplemented with $4 \%(\mathrm{v} / \mathrm{v})$ paraformaldehyde (ICN) overnight and embedded in paraffin wax. Paraffin wax was removed by immersing the sections three times in xylene for $5 \mathrm{~min}$, twice in ethanol $(100 \%, \mathrm{v} / \mathrm{v})$ for $5 \mathrm{~min}$ and twice in ethanol $(95 \%$; v/v) for $3 \mathrm{~min}$. The sections were further hydrated in $\mathrm{H}_{2} \mathrm{O}$ and PBS, and stained using the haematein-phloxine-safran method (Hould, 1995).

\section{Statistical analysis}

ANOVA was conducted using SuperANOVA software (Abacus Concepts, Berkeley, CA). Significant differences between treated and control groups were determined by using the Student's $t$ test. Differences were considered significant at $P<0.05$.

\section{Results}

The efficiency of MBP-P26h for generating antibodies was demonstrated using ELISA. Three groups each containing two male golden hamsters were immunized with 50, 100 or

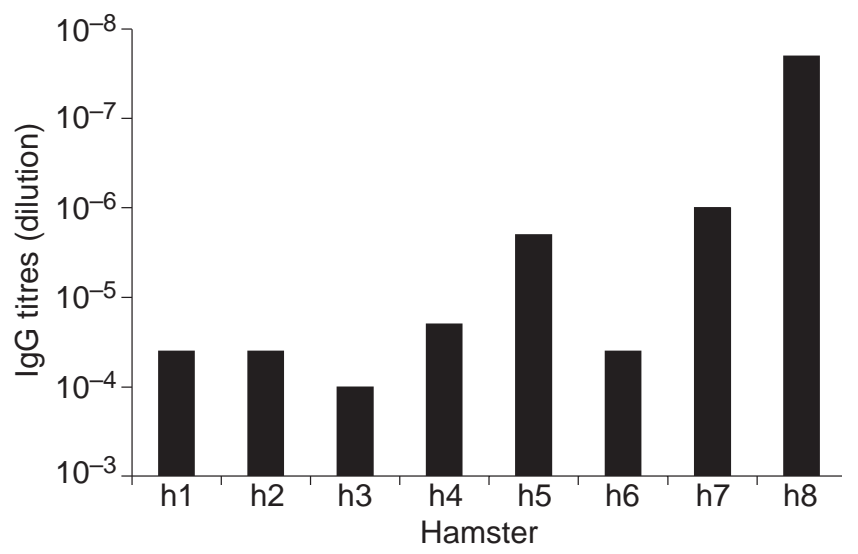

Fig. 1. IgG titres of individual male hamsters immunized with either maltose binding protein (MBP)-P26h (hamsters h1 to h6) or MBP (hamsters h7 and h8). IgG titres were determined by ELISA and show specific IgG production against P26h. Hamsters h1 and h2, h3 and h4, and h5 and h6 were immunized with 50, 100 and $150 \mu \mathrm{g}$ MBP-P26h, respectively and hamsters h7 and h8 were immunized with $150 \mu \mathrm{g}$ MBP as a negative control.

$150 \mu \mathrm{g}$ MBP-P26h, respectively, and two control male hamsters were immunized with $150 \mu \mathrm{g}$ MBP alone. All male hamsters were immunized each month until a high titre of IgGs was obtained in sera. The use of MBP-P26h generated a high and specific antibody response against P26h as shown by the use of GST-P26h in ELISA. Indeed, high IgG titres were obtained after three booster injections (Fig. 1). ELISA using MBP-P26h as a coating protein was also performed and showed that IgG titres against MBPP26h were approximately 10-100-fold higher than IgG titres against P26h, revealing an antibody response mainly directed against the MBP counterpart of the fusion protein (data not shown).

The ability of anti-P26h IgGs in sera of immunized hamsters to detect P26h in western blot analysis was verified on extracted sperm cauda epididymal proteins using primary antibodies from the sera from immunized male hamsters. Anti-P26h IgGs were not detected in the sera from all immunized hamsters. Indeed, P26h was not detected by western blot analysis when sera of two of the hamsters immunized against MBP-P26h were used. In sera in which anti-P26h IgGs reacted with P26h on western blots, inter-individual variations were noted with respect to the sensitivity of antisera to detect P26h (Fig. 2). In addition, no correlation was observed between the $\lg G$ titres and their ability to detect P26h in western blot analysis. Finally, no P26h was detected in western blots probed with antisera from male hamsters immunized with MBP alone (Fig. 2).

Male immunized hamsters were mated with superovulated females to determine the effect of active immunization on the rate of fertilization. Fertilization rates were compared between MBP-immunized and the untreated male hamsters. Eggs were collected by flushing the oviducts and fertilized eggs were counted. Active immunization against MBP-P26h 


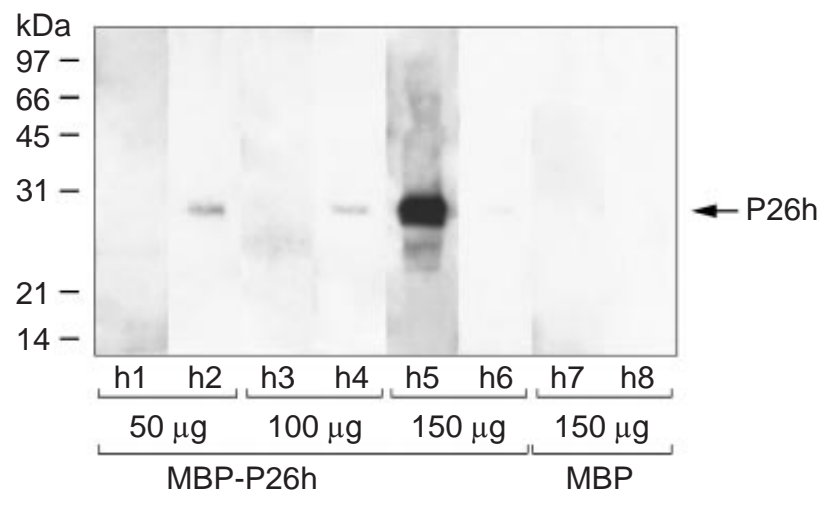

Fig. 2. Western blot analysis of extracted proteins from cauda epididymal spermatozoa probed with sera from individual hamsters immunized with different concentrations of maltose binding protein (MBP)-P26h or against MBP alone.

caused a significant decrease, $20-25 \%$, in the fertilization rate when male hamsters immunized with MBP-P26h were used for mating. No significant difference was observed between male hamsters immunized with MBP and untreated male hamsters, whereas fertilization rates were significantly lower for male hamsters immunized with MBPP26h compared with hamsters immunized with MBP and untreated hamsters. Moreover, fertilization rates between hamsters immunized with different doses of MBP-P26h were not significantly different (Fig. 3). Fertilization rates were not correlated with the anti-P26h-lgG titre of sera collected from immunized males. Again, inter-individual variations were observed regarding fertilization rates.

The efficiency of anti-MBP-P26h IgGs to inhibit spermzona pellucida binding was compared with anti-native P26h IgGs. Binding studies revealed that anti-MBP-P26h IgGs block sperm binding to the zona pellucida in a dosedependent manner. However, the efficiency of MBP-P26h IgGs was lower than that of the antiserum raised against native P26h (Fig. 4). Indeed, a significant decrease in sperm-zona pellucida binding was assessed with a smaller amount of IgGs purified from anti-native P26h antiserum than IgGs purified from anti-MBP-P26h IgGs.

Histological sections of testis and epididymis of immunized male hamsters and untreated hamsters were compared. Tissues were collected 2 weeks after the administration of the last booster injections when the highest $\lg G$ titres were reached. In comparison with tissue sections collected from hamsters immunized with MBP-P26h or MBP (not shown), untreated tissue sections showed no histopathology. Indeed, testicular sections showed normal seminiferous epithelium with spermatogenesis. Epididymal sections also revealed normal epithelium with spermatozoa within the luminal compartment, supporting the fact that normal spermatogenesis occurred in the testis (Fig. 5). Finally, morphology and motility studies were performed on epididymal spermatozoa collected from immunized hamsters.

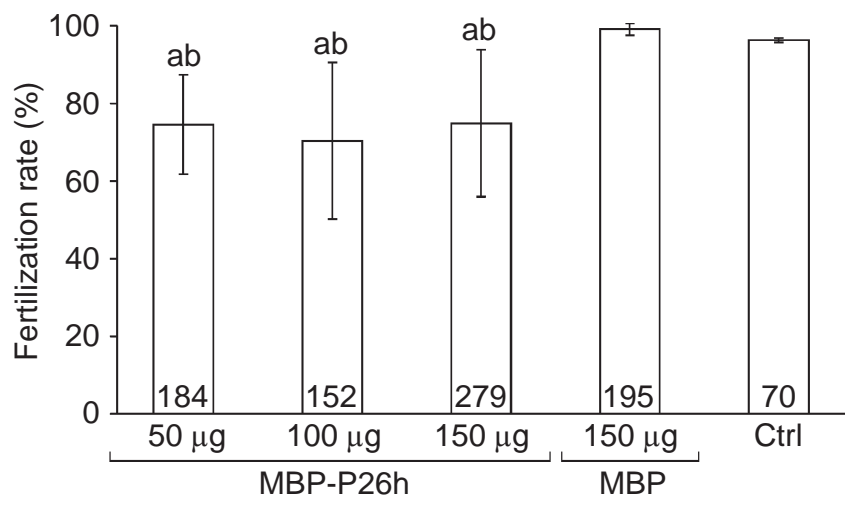

Fig. 3. Effect of immunizations with different doses of maltose binding protein (MBP)-P26h or MBP on fertilization rates in male hamsters. Numbers within bars represent the number of oocytes examined in each test. Results are expressed as a percentage of fertilized oocytes. aSignificantly different from MBP controls $(P<0.05)$. bSignificantly different from untreated controls (Ctrl) $(P<0.05)$.

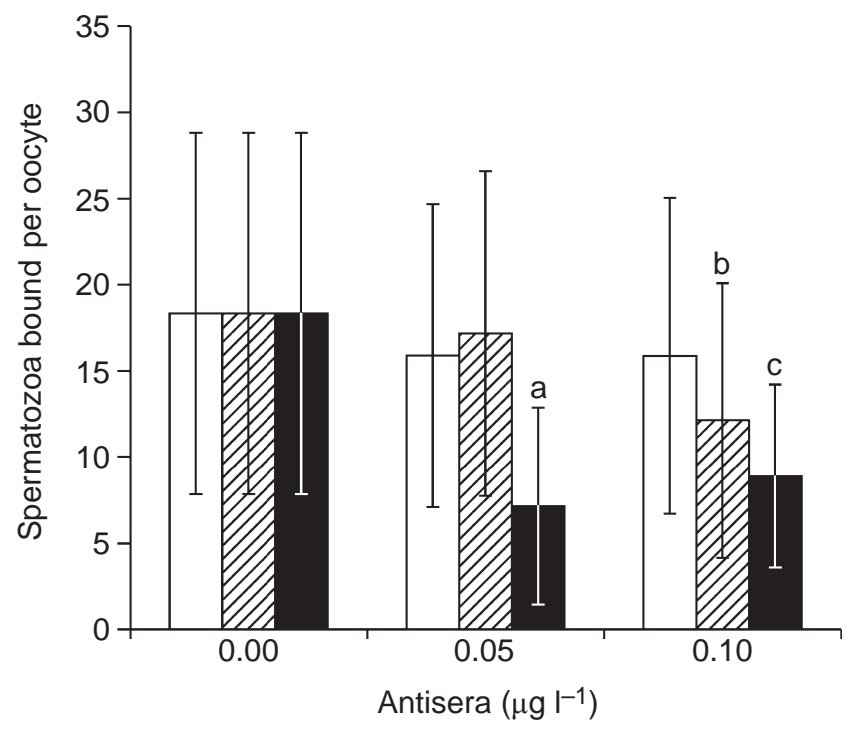

Fig. 4. The effect of anti-maltose binding protein (MBP)-P26h IgGs (四), anti-native P26h IgGs ( $\square$ ) and preimmune IgGs ( $\square$ ) on sperm-zona pellucida binding. Different amounts of IgGs were added to the in vitro fertilization medium 30 min before the addition of capacitated cauda epididymal spermatozoa. Results are expressed as the number of spermatozoa bound per oocyte. aValues significantly different from preimmune and anti MBP-P26h IgGs assays at $0.05 \mu g \mu^{-1} \quad(P<0.05)$. bValues significantly different from anti MBP-P26h assay at $0.05 \mu \mathrm{g} \mu \mathrm{I}^{-1} \quad(P<0.05)$. ${ }^{c}$ Values significantly different from preimmune assay at at $0.1 \mu \mathrm{g} \mu^{-1}(P<0.05)$.

In comparison with cauda epididymal spermatozoa collected from untreated hamsters, cauda epididymal spermatozoa from hamsters immunized with either MBP-P26h or MBP were similar (data not shown). 

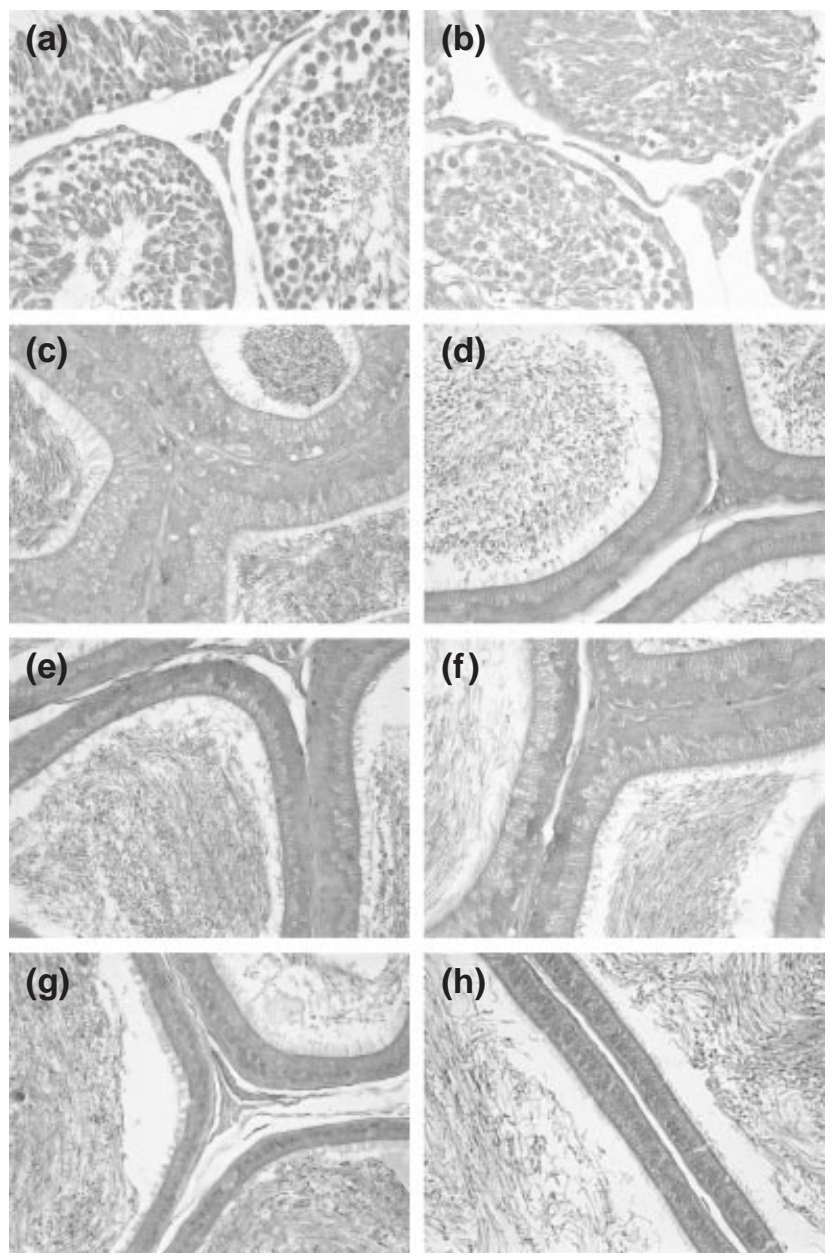

Fig. 5. Histological sections from $(a, b)$ testis, (c,d) caput epididymis, $(\mathrm{e}, \mathrm{f})$ corpus epididymis and $(\mathrm{g}, \mathrm{h})$ cauda epididymis of male hamsters. Tissue sections were collected from male hamsters immunized with maltose binding protein (MBP)-P26h (a,c,e,f) and from untreated hamsters $(b, d, f, h)$. Sections were stained by haematein-phloxine-safran method.

\section{Discussion}

Candidates for the development of a contraceptive vaccine must be specific and involved in the reproductive process. In this respect, sperm surface proteins involved in spermegg interactions are of immense interest (Naz, 1999). Using hamsters as a model, we proposed P26h as a candidate for the development of a contraceptive vaccine (Bérubé and Sullivan, 1994). P26h is a protein localized on the sperm surface covering the acrosomal cap (Bérubé and Sullivan, 1994), which binds to spermatozoa during epididymal transit (Robitaille et al., 1991; Légaré et al., 1999). Moreover, P26h is involved in sperm-egg interactions and possesses immunocontraceptive properties. In the present study, the contraceptive effect of recombinant P26h fused with MBP was assayed.
IgGs against sperm proteins in hamster and rat sera can reach the lumen of the epididymis and bind epididymal spermatozoa (Bérubé and Sullivan, 1994; Ellerman et al., 1998). As a result, the fertilization process is interrupted. Immunization with MBP-P26h was then performed to generate antibodies against P26h and, thus, to interfere with the fertilization process. Immunization of male hamsters with MBP-P26h induced production of serum antibodies against P26h and also resulted in a significant decrease, about $20-25 \%$, in the fertilization rates. In all male hamsters, immunization generated high and specific antiMBP-P26h IgGs. However, despite this antibody response, the immunodetection of P26h by western blot analysis differed among individual males. In two immunized male hamsters, antisera failed to detect the P26h in western blots, whereas in other sera detection of P26h was weak to strong. Results showed that in all immunized hamsters, the antibody response was mainly directed against the MBP counterpart of the fusion protein. This finding would explain the absent or the weak detection of P26h by western blot analysis despite the high antibody titres. No correlation was observed between the antibody titres determined by ELISA and the ability of hamster antisera to detect P26h on western blots.

Mating of immunized male hamsters with superovulated females resulted in a decrease in the rates of fertilization. Male hamsters were immunized against MBP to determine whether immunization against this protein provokes any undesirable effect. The fertilization rates obtained from males immunized with MBP alone were compared with those from untreated male hamsters of proven fertility. The absence of a difference between these groups indicates that immunization of hamsters with MBP does not interfere with normal reproduction. In all groups of hamsters immunized with MBP-P26h, a significant decrease in the rates of fertilization was observed. Thus, the reduced fertilization rates in male hamsters immunized with MBP-P26h were caused by the antibodies generated against the P26h. No significant differences were observed among animals immunized with different doses of MBP-P26h. In the present study, each group of hamsters was subjected to the same method of antigen delivery. There was no correlation between the fertilization rate and the IgG titres, or the ability of antisera to immunoreact with P26h on the western blots. These results are controversial; however, the lack of a correlation between these parameters has been reported in mice immunized against the mSp17 sperm antigen (Lea et al., 1998) and seems to indicate that serum titre and western blot analysis are not the best methods to predict the efficiency of contraceptive vaccines.

Complete immunocontraception is induced when P26h purified from cauda epididymal hamster spermatozoa is used (Bérubé and Sullivan, 1994), whereas partial inhibition is obtained when MBP-P26h, expressed in an E. coli bacterial strain is used as an immunogen. P26h fused with MBP may not be processed normally after translation, especially glycosylation. It is well known that glycosylation 
affects the antigenic properties of proteins (Sacco et al., 1986; Henderson et al., 1987) and that it is involved in gamete recognition (Ahuja, 1985; Benoff, 1997). Native P26h is glycosylated as determined by its affinity to bind Concanavalin A (Sullivan and Bleau, 1985), and the use of a non-glycosylated antigen would eliminate the possibility of generating antibody against carbohydrate moieties that may be involved in the sperm-egg interaction, as this is associated with low rate of fertilization inhibition. Moreover, it is well known that adequate protein folding increases the efficacy of a vaccine (Westhoff et al., 1997). Inadequate folding of the recombinant protein would reduce the possibility of antibody production against discontinuous epitopes present in the native P26h located on the surface of epididymal spermatozoa. The presence of the MBP counterpart of the fusion protein may also mask antigenic determinants. In other studies, purified P26h adsorbed on a nitrocellulose sheet was surgically inserted in the spleen to induce immunological infertility (Bérubé and Sullivan, 1994). In the present study, antigens were emulsified with Freund's adjuvant and administrated i.p. Administration of antigens i.p. generated higher $\lg G$ titres than did native P26h inserted in the spleen. However, despite these higher titres, the efficiency of active immunization with MBP-P26h to inhibit fertilization was lower compared with native P26h. Both systems of antigen delivery are able to generate an antibody response. However, the low rate of fertilization inhibition in the present study supports the contention that the absence of glycosylation and the inadequate folding of the MBP-P26h resulted in an inefficient contraceptive effect.

A contraceptive vaccine should be reversible with no obvious side effects to the users of the vaccine $(\mathrm{WHO}$, 1978). An effective contraceptive vaccination has already been demonstrated (Primakoff et al., 1988; Bérubé and Sullivan, 1994); however, a fully effective contraceptive vaccine with no adverse side effects is not available. Contraceptive vaccines are associated with autoimmune problems (Rhim et al., 1992; Tung et al., 1997). Furthermore, immunization with a complete protein usually generates side effects (Skinner et al., 1984; Rhim et al., 1992). It is now more common to select defined B-cell epitopes in the elaboration of contraceptive vaccines to prevent any side effect. Indeed, complete protein may contain T-cell epitopes that could generate cytotoxic T-lymphocyte responses leading to histopathology (Epifano and Dean, 1994). P26h originates in the testis (Gaudreault et al., 1999). Despite the blood-testis barrier and the limited immunomodulation that occurs in the testis (Beagley et al., 1998), the risk of side effects remains. This risk of side effects is illustrated by the testicular inflammatory reaction when male guinea-pigs are immunized against $\mathrm{PH}-20$, a testicular antigen (Tung et al., 1997). In the present study, complete P26h fused with MBP was used as the antigen for the vaccination. The absence of inflammation or orchitis is critical to assessing the potential of P26h as an antigen for immunocontraception. Thus, to eliminate the possibility that any inflammatory reaction had subsided, tissues for histological studies were collected 2 weeks after the last booster was administered when highest IgG titres were obtained. Although high titres of antibody directed against P26h were generated in the same animals, no histopathology was evident in reproductive tissues and no deleterious effects were detected on spermatozoa collected along the epididymis. In addition, indirect evidence leads to the conclusion that no cytotoxic T-cell response occurred during the immunization schedule. Indeed, cytotoxic T-cell response is associated with autoimmune orchitis leading to the irreversible arrest of spermatogenesis (Tung et al., 1997). During the present study, spermatogenesis remained unaffected as shown by the presence of spermatozoa in vaginal smears of female hamsters housed with immunized males, and by the histology of the testis at the end of the immunization schedule. Moreover, although there was a decrease in fertilization rates, spermatozoa from immunized male hamsters had the ability to fertilize in vivo. Thus, it is concluded that no cytotoxic T-cell response occurred during the study. In the present study, the use of complete P26h protein as an antigen for immunocontraception did not cause autoimmune problems as observed when testicular sperm antigens are used (Mahi-Brown et al., 1990; Tung et al., 1997).

In conclusion, the use of MBP-P26h generated a high antibody response. However, inadequate antigen presentation and a lack of glycosylation may be responsible for the partial immunocontraceptive effect observed. Mapping glycolytic epitopes and dominant B-cell of P26h involved in sperm-egg interactions conjugated with $\mathrm{T}$-cell helper epitope should prove to be an interesting approach to development of synthetic vaccines. The capacity of P26h to block fertilization without inducing a testicular or epididymal cytotoxic response indicates that this sperm antigen is a possible target for immunocontraception.

The authors wish to thank S. Picard for staining of tissue sectioning, N. Verville for technical assistance and J. Bailey for valuable criticism. This work was supported by an MRC-Canada grant to R. Sullivan.

\section{References}

Ahuja KK (1985) Carbohydrate determinants involved in mammalian fertilization American Journal of Anatomy 174 207-223

Beagley KW, Wu ZL, Pomering M and Jones RC (1998) Immune responses in the epididymis: implications for immunocontraception Journal of Reproduction and Fertility Supplement 53 235-245

Benoff S (1997) Carbohydrates and fertilization: an overview Molecular Human Reproduction 3 599-637

Bérubé B and Sullivan R (1994) Inhibition of in vivo fertilization by active immunization of male hamsters against a 26-kDa sperm glycoprotein Biology of Reproduction 51 1255-1263

Boué F, Blais J and Sullivan R (1996) Surface localization of P34H an epididymal protein, during maturation, capacitation and acrosome reaction of human spermatozoa Biology of Reproduction 54 1009-1017

Bronson R, Cooper G and Rosenfeld D (1984) Sperm antibodies: their role in infertility Fertility and Sterility 42 171-183

Chang TH, Jih MH and Wu TC (1993) Relationship of sperm antibodies in 
women and men to human in vitro fertilization, cleavage and pregnancy rate American Journal of Reproductive Immunology 30 108-112

Ellerman DA, Brantua VS, Martinez SP, Cohen DJ, Conesa D and Cuasnicu PS (1998) Potential contraceptive use of epididymal proteins: immunization of male rats with epididymal protein DE inhibits sperm fusion ability Biology of Reproduction 59 1029-1036

Epifano O and Dean J (1994) Biology and structure of the zona pellucida: a target for immunocontraception Reproduction, Fertility and Development $6319-330$

Florman HM and Wassarman PM (1985) O-linked oligosaccharides of mouse egg ZP3 account for its sperm receptor activity Cell 41 313-324

Gaudreault C, Légare C, Bérubé B and Sullivan R (1999) Hamster sperm protein, p26h: a member of the short-chain dehydrogenase/reductase superfamily Biology of Reproduction 61 264-273

Gaudreault C, El Alfy M, Légaré C and Sullivan R (2001) Expression of the hamster sperm protein p26h during spermatogenesis Biology of Reproduction 65 79-86

Goldberg E (1986) Sperm specific lactate dehydrogenase and development of a contraceptive vaccine. In Reproductive Immunology pp 137-142 Eds DA Clark and BA Croy. Elsevier Press, New York

Henderson CJ, Hulme MJ and Aitken RJ (1987) Analysis of the biological properties of antibodies raised against intact and deglycosylated porcine zonae pellucidae Gamete Research 16 323-341

Herr JC, Flickinger CJ, Homyk M, Klotz K and John E (1990) Biochemical and morphological characterization of the intra-acrosomal antigen SP-10 from human sperm Biology of Reproduction 42 181-193

Hould R (1995) Techniques d'histopathologie et de cytopathologie. In Décarie pp 153-154. Montréal

Laemmli U (1970) Cleavage of structural proteins during the assembly of the head bacteriophage T4 Nature 227 680-685

Lea IA, van Lierop MJC, Grootenhuis A, Wen Y, van Duin M and O'Rand M (1998) A chimeric sperm peptide induces antibodies and strain-specific reversible infertility in mice Biology of Reproduction 59 527-536

Légaré C, Bérubé B, Boué F, Lefièvre L, Morales CR, El-Alfy M and Sullivan $\mathbf{R}$ (1999) Hamster sperm antigen P26h is a phosphatidylinositol-anchored protein Molecular Reproduction and Development 52 225-233

Liskin L, Pile JM and Qillin WH (1983) Vasectomy safe and simple Population Reports, Series D, Male Sterilization 4 61-100

Mahi-Brown CA, VandeVoort CA, McGuinness RP, Overstreet JW, O'Hern P and Goldberg E (1990) Immunization of male but not female mice with the sperm-specific isozyme of lactate dehydrogenase (LDH-C4) impairs fertilization in vivo. American Journal of Reproductive Immunology $\mathbf{2 4}$ $1-8$

Mendelbaum SL, Diamond MP and DeCherney AH (1987) Relationship of antisperm antibodies to oocyte fertilization in in vitro fertilizationembryo transfer 47 644-651

Moudgal N and Suresh R (1995) FSH and FSH derived vaccines. In Birth Control Vaccines pp 89-100 Eds G Talwar and R Raghupathy. RG Landes Company, Austin

Naz RK (1992) Effects of antisperm antibodies on early cleavage of fertilized ova Biology of Reproduction 46 130-139

Naz RK (1996) Application of sperm antigens in immunocontraception Frontier Biosciences 1 87-95

Naz RK (1999) Vaccine for contraception targeting sperm Immunological Review 171 193-202

Naz RK and Zhu X (1997) Molecular cloning and sequencing of cDNA encoding for a novel testis-specific antigen Molecular Reproduction and Development 48 449-457

Naz RK and Zhu X (1998) Recombinant fertilization antigen-1 causes a contraceptive effect in actively immunized mice Biology of Reproduction 59 1095-1100

Naz RK, Morte C, Garcia-Framis V, Kaplan P and Martinez P (1993) Characterization of a sperm-specific monoclonal antibody and isolation of 95-kilodalton fertilization antigen-2 from human sperm Biology of Reproduction 49 1236-1244

Primakoff P, Lathrop W, Woolman L, Cowan A and Myles D (1988) Fully effective contraception in male and female guinea pigs immunized with the sperm protein $\mathrm{PH}-20$ Nature 335 543-546

Rhim SH, Millar SE, Robey F, Luo AM, Lou YH, Yule T, Allen P, Dean J and Tung KS (1992) Autoimmune disease of the ovary induced by a ZP3 peptide from the mouse zona pellucida Journal of Clinical Investigation 89 28-35

Robitaille G, Sullivan R and Bleau G (1991) Identification of epididymal proteins associated with hamster sperm Journal of Experimental Zoology 258 69-74

Sacco AG, Yurewicz EC and Subramanian MG (1986) Carbohydrate influences the immunogenic and antigenic characteristics of the ZP3 macromolecule (Mr 55 000) of the pig zona pellucida Journal of Reproduction and Fertility 76 575-585

Skinner SM, Mills T, Kirchick HJ and Dunbar BS (1984) Immunization with zona pellucida proteins results in abnormal ovarian follicular differentiation and inhibition of gonadotropin-induced steroid secretion Endocrinology 115 2418-2432

Sullivan R and Bleau G (1985) Interaction of isolated components from mammalian and egg Gamete Research 12 101-116

Talwar GP (1999) Vaccines and passive immunological approaches for the control of fertility and hormone-dependent cancers Immunological Review 171 173-192

Talwar GP, Gupta SK, Singh V, Sahal D, Iyer KS and Singh O (1985) Bioeffective monoclonal antibody against the decapeptide gonadotropinreleasing hormone: reacting determinant and action on ovulation and estrus suppression Proceedings National Academy of Sciences USA 82 1228-1231

Talwar GP, Singh O, Pal R et al. (1994) A vaccine that prevents pregnancy in women Proceedings National Academy of Sciences USA 91 8532-8536

Towbin H, Staehelin T and Gordon J (1979) Electrophoretic transfer of proteins from polyacrylamide gels to nitrocellulose sheets: procedure and some applications Proceedings National Academy of Sciences $\mathbf{7 6}$ 4350-4354

Tung KS, Primakoff P, Woolman-Gamer L and Myles DG (1997) Mechanism of infertility in male guinea pigs immunized with sperm $\mathrm{PH}-20$ Biology of Reproduction 56 1133-1141

Tyndale-Biscoe CH (1994) Virus-vectored immunocontraception of feral mammals Reproduction, Fertility and Development 6 281-287

Westhoff WE, Slootstra JW, Puijk WC, van Leeuwen L, Schaaper WM, Oonk HB and Meloen RH (1997) In vitro inhibition of the biological activity of follicle-stimulating hormone by anti-peptide antisera representing the human follicle-stimulating hormone beta subunit sequence 33-53 Biology of Reproduction 56 460-468

WHO (1978) Task force on immunological methods for fertility regulation, evaluating the safety and efficacity of placental antigen vaccines for fertility regulation Clinical and Experimental Immunology 33360

Yanagimachi R (1982) In vitro sperm capacitation and fertilization of golden hamster eggs in a chemically defined medium. In In Vitro Fertilization and Embryo Transfer pp 65-76 Eds R Yanagimachi, E Hafez and K Semm. Alan R Liss, New York

Zhu X and Naz RK (1998) Cloning and sequencing of cDNA encoding for a human sperm antigen involved in fertilization Molecular Reproduction and Development 51 176-183

Received 23 March 2001.

First decision 29 May 2001.

Final version received 25 October 2001.

Accepted 25 October 2001. 